\title{
Evaluation of endometrial causes of postmenopausal bleeding with it's correlation with endometrial thickness and hysteroscopy findings and endometrial tissue histopathology
}

\author{
Saurabh V. Bhangale ${ }^{1}$, Shailja Sharma ${ }^{1 *}$, Asmita Patil², Beena Kumari ${ }^{1}$
}

\author{
${ }^{1}$ Department of Obstetrics and Gynecology, Dr. Babasaheb Ambedkar Memorial Central Railway Hospital, Byculla \\ (East), Mumbai, Maharashtra, India \\ ${ }^{2}$ Department of Obstetrics and Gynecology, Rajiv Gandhi Medical College and Chatrapati Shivaji Maharaj Hospital, \\ Kalwa, Thane, Maharashtra, India
}

Received: 06 December 2019

Revised: 05 May 2020

Accepted: 11 May 2020

\author{
*Correspondence: \\ Dr. Shailja Sharma, \\ E-mail: dr.shailja2014@gmail.com
}

Copyright: (c) the author(s), publisher and licensee Medip Academy. This is an open-access article distributed under the terms of the Creative Commons Attribution Non-Commercial License, which permits unrestricted non-commercial use, distribution, and reproduction in any medium, provided the original work is properly cited.

\begin{abstract}
Background: Postmenopausal bleeding (PMB)accounts for 5\% of gynecology visit. All with unexpected uterine bleeding should be evaluated for endometrial carcinoma since this potentially lethal disease is the cause of bleeding in approximately 10 percent patients (range 1 to 25 percent, depending upon risk factors). The aim of the study was to evaluate endometrial causes of postmenopausal bleeding (PMB) with it's correlation with endometrial thickness (ET)and hysteroscopy findings and endometrial tissue histopathology.

Methods: A total 50 consecutive cases of PMB fulfilling the inclusion and exclusion criteria and giving informed consent were selected. Each patient was subjected to transvaginal sonography (TVS) in which uterus, adnexa and endometrial thickness (ET) was assessed. Then hysteroscopy and/or dilation and curettage was scheduled at subsequent visit. Endometrial sample was sent for histopathological examination. Sensitivity, specificity, positive predictive value (PPV), negative predictive value (NPV) and diagnostic accuracy was calculated for ET by TVS and hysteroscopy findings, considering histopathological diagnosis as the gold standard.

Results: Most common endometrial cause of PMB was atrophic endometrium (44\%). The other causes were endometrial carcinoma (18\%), endometrial hyperplasia (18\%), endometrial polyp (12\%), endometritis (4\%), and leiomyoma (4\%). The diagnostic accuracy of ET by TVS at a cut-off point of $5 \mathrm{~mm}$ was $94 \%$ with sensitivity $89.3 \%$, specificity $100 \%$, PPV $100 \%$ and NPV $88 \%$. The diagnostic accuracy of hysteroscopy was $98 \%$ with sensitivity $96.4 \%$, specificity $100 \%$, PPV $100 \%$ and NPV $95.7 \%$.

Conclusions: Being relatively cheap, easily accessible, non-invasive, TVS with ET measurement should first line investigation in the evaluation of women with postmenopausal bleeding with suspected endometrial pathology. Although hysteroscopy is more specific and sensitive, in poor resource settings it should be limited to cases with illdefined endometrial lining, recurrent/ persistent bleeding and cases with endometrial thickness greater than $5 \mathrm{~mm}$ irrespective of endometrial echotexture.
\end{abstract}

Keywords: Endometrial thickness, Hysteroscopy, Postmenopausal bleeding, Transvaginal sonography

\section{INTRODUCTION}

Postmenopausal bleeding (PMB) refers to any genital tract bleeding in a menopausal woman i.e. twelve months or more of amenorrhea in a woman of menopausal age. It does not include expected cyclic bleeding that occurs in women taking cyclic postmenopausal hormone therapy. It accounts for about 5 percent of office gynecology visits. ${ }^{1}$ 
All postmenopausal women with unexpected uterine bleeding should be evaluated for endometrial carcinoma since this potentially lethal disease is the cause of bleeding in approximately 10 percent patients (range 1 to 25 percent, depending upon risk factors). ${ }^{2}$ However, the most common cause of bleeding in these women is atrophy of the vaginal mucosa or endometrium. ${ }^{3}$ In the early menopausal years, endometrial hyperplasia, polyps, and submucosal fibroids are also common etiologies. ${ }^{4}$ The dictum is that "any genital tract bleeding occurring after the menopause must be considered as indicative of malignancy unless proved otherwise". Due to increased life expectancy, women spend one third of their life span in postmenopausal age. Due to unhealthy lifestyle, women are at increased risk of malignancies including genital tract malignancies.

Because transvaginal sonography in postmenopausal patients with bleeding has an extremely high negative predictive value, it is a reasonable first approach. But an endometrial thickness of greater than $4 \mathrm{~mm}$ is not diagnostic of any particular pathology and cannot be relied on to exclude disease. ${ }^{5-7}$

Hysteroscopy may be performed in an office setting with or without minor anaesthesia or in the operating room with regional or general anaesthesia with all due risk of anaesthesia and procedure. Hysteroscopic evaluation can be diagnostic for direct visualisation of the uterine cavity as well as therapeutic like targeted endometrial biopsy, polypectomy etc. ${ }^{8}$

\section{Aims and Objectives}

- To evaluate the various endometrial causes of postmenopausal bleeding.

- To correlate the various endometrial causes of postmenopausal bleeding with endometrial thickness (by transvaginal sonography) and hysteroscopy findings.

- To determine the diagnostic value of endometrial thickness (by transvaginal sonography) and hysteroscopy in patients with post-menopausal bleeding with histopathological diagnosis taken as gold standard.

\section{METHODS}

A hospital based observational (screening test) study from November 2014 to November 2016, conducted at department of obstetrics and gynecology, Dr. Babasaheb Ambedkar Memorial Central Railway Hospital, Byculla, Mumbai, Maharashtra, India

\section{Sample size calculation and sampling technique:}

Sample size (n) based on sensitivity:

$$
n=\frac{Z^{2} 2(1-\alpha / 2) \times \mathrm{Sn} \times(1-\mathrm{Sn})}{\mathrm{L} 2}
$$

Where,

$\mathrm{n}=$ required sample size,

$\mathrm{SN}=$ anticipated sensitivity (of endometrial thickness, taken as $85 \%$ based on study by Elewa AM et al. ${ }^{9}$

$\alpha=$ size of the critical region ( $1-\alpha$ is the confidence level),

$\mathrm{Z}_{1-\alpha / 2}=$ standard normal deviate corresponding to the specified size of the critical region $(\alpha)$, at $95 \%$ confidence level, its value is 1.96 .

$\mathrm{L}$ - allowable error (taken as $10 \%$ with power of study as $90 \%)$

$\mathrm{n}-(1.96)^{2} \times 0.85(1-0.85) /(0.1)^{2}$

n-50 (approx.)

Thus, final sample size was taken as 50 cases. Consecutive type of non-probability sampling was used for selection of study subjects. A total of 50 consecutive cases of postmenopausal bleeding (PMB) fulfilling the eligibility criteria and giving informed consent were taken up for the study.

\section{Inclusion criteria}

- Period of amenorrhea 12 months or more

- $\quad$ Age more than 40 years.

\section{Exclusion criteria}

- Patients who have undergone hysterectomy

- Known cases of blood dyscrasias/anti-coagulant therapy/liver pathology/other medical disorders

- Women on HRT / SERMs/hormonal therapy.

- Trauma to reproductive organs

- Foreign body in reproductive tract

- Cases with non-endometrial causes of postmenopausal bleeding like bleeding from cervical, vaginal, vulval lesions

- Women with diagnosis of bleeding from urethra and anal orifice

- Women who do not want to participate in trial

- Pregnancy

- Age less than 40 years.

Each patient presenting with PMB underwent a preliminary assessment by detailed history including complete medical and surgical history and reproductive history with special attention to hypertension, diabetes, obesity and thorough clinical examination. All relevant abnormal findings in history and examination were noted. Data was collected in a pre-designed format for all women. A provisional diagnosis was made and each patient was subjected to appropriate modalities of investigations. When decision was taken to do TVS and hysteroscopy and/or dilatation and curettage, an informed, valid and written consent of all cases for either/both procedures was taken after explaining the procedure in detail and possible complications of procedure in language best understood by patient and relatives. 
The study protocol included a trans-vaginal sonography (TVS) in first visit. The uterus and the adnexa were visualised using a 7.5 megahertz vaginal probe transducer. Uterine contour was evaluated for any specific focal lesion like presence of intramural or submucosal lesions like endometrial polyp or fibroid. The endometrial strip was commented upon appearance and thickness. Specific findings were recorded. The counter of the endometrial strip was assessed in midline sagittal plane and the point of maximum thickness of the endometrial strip was measured on a frozen image at 1.5 times magnification and it was termed as endometrial thickness (ET). Endometrial thickness was measured as a double layer in the longitudinal plane at the widest point within the fundus with the entire endocervical and endometrial strip visible. The ultrasonographic criteria considered to define "normal" was endometrial thickness $(</=5 \mathrm{~mm})$ and regular endometrial appearance. All other findings not satisfying normal endometrium criteria were considered "abnormal".

Hysteroscopy and/or dilation and curettage under total intra-venous anaesthesia (TIVA) was then scheduled at subsequent visit after all pre-operative work up and anaesthesia fitness. Hysteroscopy was performed using a $5 \mathrm{~mm}$ single channel hysteroscope with a fibro-optic light source; normal saline was used as continuous flow distending medium and the procedure was performed under direct video monitoring.

The endometrium was described as "atrophic" when seemed to be thin and pale and categorized as "normal". Endometrial lesions like endometrial polyp, leiomyoma if noted were categorized under "other specific lesions". All other findings excluding above two mentioned criteria were considered "abnormal thickened endometrium". This may include thickened endometrium, polypoidal appearance and irregular growth of the endometrium with atypical vascularisation. Abnormal thickened endometrium and other specific lesions were categorized as "abnormal". Hysteroscopy directed biopsy was taken in appropriately selected cases and therapeutic hysteroscopy done in the same sitting if feasible in focal endometrial lesion. In the same sitting the endometrial biopsy was performed by curetting the uterine cavity in clock wise or anti-clock wise direction starting from fundus down to internal os by dilation and curettage by sharp curette in all cases and the endometrial tissue sample was sent for histopathological examination after preserving sample in $10 \%$ formalin.

A detailed histopathological examination of haematoxylin and eosin stained sections was carried out and the histopathological diagnosis were grouped in following categories:

- Atrophy

- Leiomyoma

- Endometrial polyp

- Endometrial hyperplasia
- Endometritis and;

- Endometrial carcinoma.

Curettage sample if insufficient for the histopathological examination was included in atrophy group and categorized as "normal" whereas other histopathological findings were considered "abnormal".

After completing the protocol examinations, women were re-evaluated in an outpatient clinic and were submitted to medical or surgical therapy if necessary. The other necessary investigations were individualized and performed in order to reach the final diagnosis like magnetic resonance imaging (MRI) in endometrial carcinoma. In each case the treatment was individualized and modalities of treatment were documented in brief. All procedures were followed as per the ethical guidelines approved by the authorities of study hospital.

\section{Statistical analysis}

Statistical analysis was carried out using SPSS software ver. 21 after collecting patient data as master chart. Demographic data was presented as frequency with percentage and mean with standard deviation wherever suitable. The comparison and correlation between endometrial thickness (by TVS) and hysteroscopy findings with endometrial tissue histopathology (taken as gold standard) was done (Table 1).

Table 1: Calculation of screening test parameters. ${ }^{10}$

\begin{tabular}{|llll|}
\hline \multirow{2}{*}{$\begin{array}{l}\text { Screening } \\
\text { test }\end{array}$} & \multicolumn{2}{l|}{$\begin{array}{l}\text { Diagnosis (by gold } \\
\text { standard test) }\end{array}$} & Total \\
\cline { 2 - 4 } Positive & Negative & \\
\hline Positive & A (TP) & B (FP) & A+B \\
\hline Negative & C (FN) & D (TN) & C+D \\
\hline Total & A+C & B+D & Total \\
\hline
\end{tabular}

\section{Sensitivity $=A / A+C \times 100$}

The sensitivity of a clinical test refers to the ability of the test to correctly identify those patients with the disease.

$$
\text { Sensitivity }=\frac{\text { True positive }}{\text { True positive }+ \text { False negative }}
$$

\section{Specificity $=D / B+D \times 100$}

The specificity of a clinical test refers to the ability of the test to correctly identify those patients without the disease.

$$
\text { Specificity }=\frac{\text { True negative }}{\text { True negative }+ \text { False positive }}
$$

\section{Positive predictive value $=A / A+B \times 100$}

The PPV of a test is a proportion that is useful to clinicians since it answers the question: 'How likely is it 
that this patient has the disease given that the test result is positive?'

$$
\text { Positive predictive value }=\frac{\text { True positive }}{\text { True positive }+ \text { False positive }}
$$

\section{Negative predictive value $=D / C+D \times 100$}

The NPV of a test answers the question: 'How likely is it that this patient does not have the disease given that the test result is negative?'

$$
\text { Negative predictive value }=\frac{\text { True negative }}{\text { True negative }+ \text { False negative }}
$$

\section{Accuracy $=A+D /$ Total $\times 100$}

The accuracy of a clinical test refers to its overall diagnostic efficacy in correctly identifying those patients with and without the disease.

$$
\text { Accuracy }=\frac{\text { True positive }+ \text { True negative }}{\text { Total population }}
$$

\section{RESULTS}

Mean age of the study population was 52.32 years with $22 \%$ of the females above 60 years of age (Table 2 ).

Table 2: Distribution of study population based on age group.

\begin{tabular}{|lll|}
\hline Age group (years) & $\mathbf{N}$ & $\%$ \\
\hline $40-45$ & 2 & $4.0 \%$ \\
\hline $46-50$ & 18 & $36.0 \%$ \\
\hline $51-55$ & 11 & $22.0 \%$ \\
\hline $56-60$ & 8 & $16.0 \%$ \\
\hline$>60$ & 11 & $22.0 \%$ \\
\hline Total & 50 & $100.0 \%$ \\
\hline
\end{tabular}

Most of the females were from lower socio-economic stratum $(60 \%)$ of society as per modified Kuppuswamy classification (Table 3).

Table 3: Distribution of study population based on socio-economic status.

\begin{tabular}{|lll|}
\hline Socio-economic status & $\mathbf{N}$ & $\%$ \\
\hline Upper & 2 & $4.0 \%$ \\
\hline Upper Middle & 7 & $14.0 \%$ \\
\hline Lower Middle & 11 & $22.0 \%$ \\
\hline Upper Lower & 16 & $32.0 \%$ \\
\hline Lower & 14 & $28.0 \%$ \\
\hline Total & 50 & $100.0 \%$ \\
\hline
\end{tabular}

Only one female was nulliparous while most were between para 1 to para 4 .

About $8 \%$ of the females had parity 5 or above (Table 4 ). Period of menopause in most of the females was between
5-15 years $(50 \%)$. Duration above 15 years and below 5 years was seen in $18 \%$ and $32 \%$ females (Table 5).

Table 4: Distribution of study population based on parity.

\begin{tabular}{|lll|}
\hline Parity & N & $\%$ \\
\hline Nullipara & 1 & $2.0 \%$ \\
\hline Para 1-2 & 12 & $24.0 \%$ \\
\hline Para 3-4 & 33 & $66.0 \%$ \\
\hline Para 5 or more & 4 & $8.0 \%$ \\
\hline Total & 50 & $100.0 \%$ \\
\hline
\end{tabular}

Table 5: Distribution of study population based on period of menopause.

\begin{tabular}{|lll|}
\hline Period of menopause (years) & $\mathbf{N}$ & $\%$ \\
\hline$<5$ & 16 & $32.0 \%$ \\
\hline 5 to 10 & 12 & $24.0 \%$ \\
\hline 11 to 15 & 13 & $26.0 \%$ \\
\hline 15 to 20 & 7 & $14.0 \%$ \\
\hline$>20$ & 2 & $4.0 \%$ \\
\hline Total & 50 & $100.0 \%$ \\
\hline
\end{tabular}

Most common associated co-morbidities were DM $(18 \%)$, obesity (16\%), HT (10\%) and hypothyroidism $(6 \%)$.

Most common endometrial pathology was atrophic endometrium (44\%). Endometrial carcinoma was observed in $18 \%$ females. Other findings in cases of postmenopausal bleeding were endometrial hyperplasia $(18 \%)$, polyp (12\%) endometritis $(4 \%)$ and leiomyoma (4\%) (Table 6).

Table 6: Distribution of study population based on type of endometrial finding (histopathology).

\begin{tabular}{|lll|}
\hline Endometrial finding (histopath) & $\mathbf{N}$ & $\%$ \\
\hline Atrophy & 22 & $44.0 \%$ \\
\hline Hyperplasia & 9 & $18.0 \%$ \\
\hline Carcinoma & 9 & $18.0 \%$ \\
\hline Polyp & 6 & $12.0 \%$ \\
\hline Leiomyoma & 2 & $4.0 \%$ \\
\hline Endometritis & 2 & $4.0 \%$ \\
\hline Total & 50 & $100.0 \%$ \\
\hline
\end{tabular}

Atrophic endometrium found in 22 out of 50 study participants was reported as Normal in histopathology (44\%) report while all other findings in 28 out of 50 study participants were reported as abnormal (56\%).

Endometrial thickness below $5 \mathrm{~mm}$ was seen in $50 \%$ cases and it was between $6-10 \mathrm{~mm}$ in $30 \%$ cases and above $10 \mathrm{~mm}$ in $20 \%$ cases (Table 7). Endometrial thickness less than $5 \mathrm{~mm}$ was observed in 25 out of 50 study participants which was considered normal $(50 \%)$ and more than $5 \mathrm{~mm}$ was observed in remaining 25 out of 
50 study participants which was considered abnormal $(50 \%)$.

Table 7: Distribution of study population based on endometrial thickness measured on TVS.

\begin{tabular}{|lll|}
\hline Endometrial thickness in mm (TVS) & $\mathbf{N}$ & $\%$ \\
\hline$</=5 \mathrm{~mm}$ & 25 & $50.0 \%$ \\
\hline $6-10 \mathrm{~mm}$ & 15 & $30.0 \%$ \\
\hline$>10 \mathrm{~mm}$ & 10 & $20.0 \%$ \\
\hline Total & 50 & $100.0 \%$ \\
\hline
\end{tabular}

Following figure shows the correlation of endometrial thickness with various findings as observed on histopathology. All cases of endometrial ca (9/9) and(1/9)case of hyperplasia were showing thickness above $10 \mathrm{~mm}$. Remaining (8/9) cases of hyperplasia, $(5 / 6)$ cases of polyp and all cases of leiomyoma (2/2) had thickness between 6-10 mm. (1/6) cases of polyp and all cases of endometrial atrophy (22/22) and endometritis (2/2) had thickness below $5 \mathrm{~mm}$ (Figure 1).



Figure 1: Comparison of endometrial finding (histopath) with endometrial thickness.

The diagnostic accuracy of endometrial thickness by trans-vaginal sonography in differentiating endometrial pathology was 94\% with sensitivity and specificity of $89.3 \%$ and $100 \%$ respectively. PPV and NPV were found to be $100 \%$ and $88 \%$ respectively (Table 8 ).

Table 8: Diagnostic accuracy of endometrial thickness by TVS for differentiating endometrial pathology.

\begin{tabular}{|llll|}
\hline $\begin{array}{l}\text { Endometrial } \\
\text { thickness in } \\
\text { mm }(\text { TVS) }\end{array}$ & Normal & Abnormal & Total \\
\hline$</=5$ & 22 & 3 & 25 \\
\hline$>5$ & 0 & 25 & 25 \\
\hline Total & 22 & 28 & 50 \\
\hline
\end{tabular}

Diagnostic accuracy- $94 \%$, sensitivity- $89.3 \%$, specificity-100\%, PPV- 100\%, NPV-88\%.
On hysteroscopy, atrophic endometrium was seen in $46 \%$ cases while abnormal thickened endometrium was seen in $36 \%$ cases. Specific lesion like polyps and leiomyoma were seen in $18 \%$ cases (Table 9). In final hysteroscopy report, 23 out of 50 study participants with atrophic endometrium were considered as normal (46\%) and rest findings 27 out of 50 study participants were considered abnormal (54\%).

Table 9: Distribution of study population based on hysteroscopy findings.

\begin{tabular}{|lll|}
\hline Hysteroscopy report & $\mathbf{N}$ & $\%$ \\
\hline Atrophic & 23 & $46.0 \%$ \\
\hline Abnormal thickened endometrium & 18 & $36.0 \%$ \\
\hline Other specific lesions & 9 & $18.0 \%$ \\
\hline Total & 50 & 100.0 \\
\hline
\end{tabular}

Table 10: Diagnostic accuracy of hysteroscopy for PMB.

\begin{tabular}{|llll|}
\hline $\begin{array}{l}\text { Hysteroscopy } \\
\text { report }\end{array}$ & Histopathology & Total \\
\cline { 2 - 3 } & Normal & Abnormal & \\
\hline Normal & 22 & 1 & 23 \\
\hline Abnormal & 0 & 27 & 27 \\
\hline Total & 22 & 28 & 50 \\
\hline
\end{tabular}

The diagnostic accuracy of hysteroscopy for cases of PMB was $98 \%$ with sensitivity and specificity of $96.4 \%$ and $100 \%$ and positive predictive value and negative predictive value of $100 \%$ and $95.7 \%$ respectively (Table 10).

Diagnostic accuracy-98\%, sensitivity-96.4\%, specificity$100 \%$, PPV-100\%, NPV-95.7\%.

\section{DISCUSSION}

The present study was conducted with the aim of evaluating various endometrial causes of postmenopausal bleeding and correlate various causes with endometrial thickness and to determine the diagnostic value of endometrial thickness by transvaginal ultrasonography and hysteroscopy with endometrial histopathology as good standard.

\section{Demographic profile}

Mean age of the study subjects was 52.32 years and $(40 \%),(38 \%)$ and $(22 \%)$ of the females with postmenopausal bleeding (PMB) were between 40-50 years, 51-60 years and above 60 years of age respectively.

Most of the females were from lower socio-economic stratum $(60 \%)$ of society as per modified Kuppuswamy classification. The mean age in the study by Sousa $\mathrm{R}$ et al, was 62.1 years, while it was 61.9 years and 54.4 years in studies by Yela AD et al, and Kaul $\mathrm{I}$ et al, respectively. ${ }^{11-13}$ 
Verma $\mathrm{R}$ et al, in their study found that incidence of PMB between the ages of 40-50 years was (45\%) with mean age as 50.34 years. ${ }^{14}$

Peak incidence found by Naik $\mathrm{V}$ et al, was 45-50 years for postmenopausal bleeding and 56-65 years for malignancy. ${ }^{15}$ Sengupta et al, found maximum number of postmenopausal bleeding cases in the age group of 50-59 years $(80 \%){ }^{16}$

\section{Obstetric history}

Only one female (2\%) was nulliparous while most $(90 \%)$ were between para 1 to para 4 . About $(8 \%)$ of the females had parity 5 or above. In a study by Yela AD et al, only $(5 \%)$ females were nullipara. ${ }^{12}$ In a study by Kaul I et al. (4\%) females were nulliparous while $(6 \%)$ were para $>6 .{ }^{13}$ Sengupta and Vermaet al, also showed similar distribution. ${ }^{14,16}$

\section{Medical co-morbidities}

Most common associated co-morbidities were DM (18\%), Obesity (16\%), HT (10\%) and hypothyroidism $(6 \%)$. Most common associated co-morbidities observed in the study of Sousa R et al, were Hypertension (36.2\%) and diabetes (11.6\%). ${ }^{11}$ Common co-morbidities as observed by Kaul I et al, were hypertension (20\%), Obesity (16\%) and diabetes (12\%). ${ }^{13}$

\section{Endometrial pathology}

Most common endometrial pathology was atrophic endometrium (44\%). Endometrial carcinoma was observed in $(18 \%)$ females. Other findings in cases of post-menopausal bleeding were hyperplasia (18\%), endometrial polyp (12\%), endometritis (4\%), and leiomyoma $(4 \%)$.

The following observations were made in the study by Kaul I et al, normal postmenopausal atrophic endometrium in $21(42 \%)$ and hormonal effects in 5 $(10 \%)$, endometrial hyperplasia was diagnosed in 9 (18\%), a polyp was found in $4(8 \%)$, endometritis was found in $2(4 \%)$ and endometrial carcinoma was the histopathological report of $5(10 \%)$ cases. $^{13}$

Sousa $\mathrm{R}$ et al, in their study observed following pathologies in cases of PMB: normal endometrium $(7.2 \%)$, atrophy $(34.8 \%)$, cystic atrophy $(1.4 \%)$, tuberculous endometritis $(1.4 \%)$, polyps $(17.4 \%)$, leiomyoma $(1.4 \%)$, non-atypical hyperplasia $(4.3 \%)$, atypical hyperplasia (1.4\%) and endometrial carcinoma $(13.0 \%){ }^{11}$ Gao et al, also observed that most common cause of postmenopausal bleeding was atrophic endometrium $($ malignant lesions $=27 \%$; benign lesions $=$ $73 \%)^{17}$

Results observed by Naik V et al, were atrophic endometrium with senile cystic atrophy (16.3\%), proliferative endometrium $(8.6 \%)$, endometrial hyperplasia with or without atypia $(13.46 \%)$, endometrial polyp (2.8\%), endometrial adenocarcinoma (9.6\%). ${ }^{15}$

\section{Endometrial thickness}

In present study, endometrial thickness below $5 \mathrm{~mm}$ was seen in $(50 \%)$ cases while above $10 \mathrm{~mm}$ was seen in $(20 \%)$ cases. In $(30 \%)$ cases, it was between $6-10 \mathrm{~mm}$. All (9/9) (100\%) cases of endometrial carcinoma and (1/9) $(11.11 \%)$ cases of hyperplasia were showing thickness above $10 \mathrm{~mm}$. Remaining (8/9) (88.89\%) cases of hyperplasia, (5/6) $(83.33 \%)$ endometrial polyp and all cases of leiomyoma (2/2) $(100 \%)$ had thickness between 6-10 mm. (1/6) (16.67\%) endometrial polyp and all cases of endometrial atrophy (22/22) (100\%) and endometritis $(2 / 2)(100 \%)$ had thickness below $5 \mathrm{~mm}$.

The diagnostic accuracy of endometrial thickness by TVS at a cut-off point of $5 \mathrm{~mm}$ in differentiating endometrial pathology was $94 \%$ with sensitivity and specificity of $89.3 \%$ and $100 \%$ and positive predictive value and negative predictive value of $100 \%$ and $88 \%$ respectively

Kaul I et al, observed that at a cut-off limit of $>5 \mathrm{~mm}$ for endometrial thickness indicating pathologic endometrium, the sensitivity and specificity of TVS was $100 \%$ and $80 \%$ respectively and a predictive value as a positive test, as a negative test and accuracy was $76.9 \%$, $100 \%$ and $89 \%$ respectively. ${ }^{13}$

Ahmed JA et al, observed that by using $5 \mathrm{~mm}$ endometrial thickness as cut off value for atrophic endometrium, transvaginal sonography had $85 \%$ sensitivity, $96.7 \%$ specificity and accuracy of $92 \%$ in cases of postmenopausal bleeding. ${ }^{18}$

Karlson B et al, ${ }^{19}$ in a similar study observed that at endometrial thickness of $4 \mathrm{~mm}$ or more the sensitivity and specificity of transvaginal sonography to diagnose endometrial abnormality were $100 \%$ and $75 \%$ respectively.

This study results with cut-off level of $>5 \mathrm{~mm}$ also agrees with results of Bakour et al, Grandberg S et al, Cacciatore et al and Nasri et al. ${ }^{20-23}$

\section{Hysteroscopy}

On hysteroscopy, atrophic endometrium was seen in (46\%) cases while abnormal thickened endometrium was seen in $(36 \%)$ cases. Other specific lesions like endometrial polyps and lieomyomas were seen in (18\%) cases.

So, in final hysteroscopy report, authors took (46\%) cases with atrophic endometrium as normal and rest (54\%) as abnormal. The diagnostic accuracy of hysteroscopy for cases of PMB was $98 \%$ with sensitivity and specificity of $96.4 \%$ and $100 \%$ and positive predictive value and 
negative predictive value of $100 \%$ and $95.7 \%$ respectively.

In the study by Sousa $\mathrm{R}$ et al, for the assessment of endometrial pathology as a whole, transvaginal sonography revealed sensitivity $79.5 \%$, specificity $88 \%$, positive predictive value $92.1 \%$, negative predictive value $71 \%$; and hysteroscopy revealed sensitivity $97.7 \%$, specificity $92 \%$, positive predictive value $95.5 \%$, negative predictive value $95.8 \% .^{11}$

In a study, Yela $\mathrm{AD}$ et al, observed that, ultrasound showed high sensitivity and low specificity, with diagnostic accuracy of $53.7 \%$, whereas hysteroscopy showed high sensitivity and specificity, with accuracy of $88.7 \% .^{12}$

In a study by Mathlouthi $N$, Slimani $O$ et al, the sensitivity, the specificity, the positive predictive value and negative predictive values of the transvaginal ultrasonography is respectively $93.75 \%, 87.5 \%, 83.3 \%$ and $95.45 \% .{ }^{24}$ In the other part, hysteroscopy seems more performant in the diagnosis of intrauterine abnormalities with the respective values: $100 \%, 95.83 \%, 94.11 \%$ and $100 \%$.

Authors thus concluded that both transvaginal sonography and hysteroscopy were found to be useful investigations for evaluation of endometrial pathology in cases of postmenopausal bleeding but hysteroscopy has more sensitivity, specificity and accuracy. Since transvaginal sonography is relatively cheap, easy, noninvasive and needs no anesthesia, it should be used as first line investigation in the evaluation of women with postmenopausal bleeding with suspected endometrial pathology. Although hysteroscopy is more specific and sensitive, in poor resource settings it should be limited to cases with ill-defined endometrial lining, recurrent/ persistent bleeding, risk factors for endometrial carcinoma and cases with endometrial thickness greater than $5 \mathrm{~mm}$ irrespective of endometrial echo texture.

Limitations of this study were as it is a hospital-based study with relatively small sample size, the results of this study cannot be extrapolated to general population.

Long term follow-up of patients was not done for recurrence, progression and complications of the various endometrial lesions found.

Inter observer variation are possible during transvaginal ultrasonography and hysteroscopic evaluation.

\section{CONCLUSION}

This study results showed that transvaginal ultrasonography is an important investigation for evaluation of endometrial pathology in cases of postmenopausal bleeding. Since transvaginal ultrsonography is relatively cheap, easy, non-invasive and needs no anesthesia, it should be used as first line investigation in the evaluation of women with postmenopausal bleeding with suspected endometrial pathology. However, when endometrial thickness measured by transvaginal ultrasonography was found to be $\langle/=5 \mathrm{~mm}$, the risk for abnormal endometrial pathology could be safely ruled out. Thereby authors concluded that when endometrial thickness was found to be $>5 \mathrm{~mm}$, the possibility of abnormal endometrial findings on histopathology was high.

Although hysteroscopy is more specific, sensitive and accurate, in poor resource settings it should be limited to cases with ill-defined endometrial lining, recurrent/ persistent bleeding, risk factors for endometrial carcinoma and cases with endometrial thickness greater than $5 \mathrm{~mm}$ irrespective of endometrial echotexture.

However, if the resources are available, hysteroscopy should be done in all women with postmenopausal bleeding with suspected endometrial pathology. Hysteroscopy can also be used for simultaneous therapeutic interventions if feasible.

Funding: No funding sources

Conflict of interest: None declared

Ethical approval: Not required

\section{REFERENCES}

1. Moodley M, Roberts C. Clinical pathway for the evaluation of postmenopausal bleeding with an emphasis on endometrial cancer detection. J Obstet Gynaecol. 2004;24:736.

2. Prendergast EN, Misch E, Chou YA, Roston A, Patel A. Insufficient endometrial biopsy results in women with abnormal uterine bleeding. Obstet Gynecol. 2014;123:180S-S.

3. Smith PP, O'Connor S, Gupta J, Clark TJ. Recurrent postmenopausal bleeding: a prospective cohort study. J Minim Invasive Gynecol 2014; $21: 799$.

4. Laddad MM, Kshirsagar N, Patil S, Shinde G, Bhosale R. Study of adolescent abnormal uterine bleeding (AUB) and its outcome-in tertiary centre KIMS Karad. J Evolut Med Dent Sci. 2015;4(69):12043-51.

5. Goldstein SR, Nachtigall M, Snyder JR, Nachtigall L. Endometrial assessment by vaginal ultrasonography before endometrial sampling in patients with postmenopausal bleeding. Am J Obstet Gynecol. 1990;163:119-23.

6. Varner RE, Sparks JM, Cameron CD, Roberts LL, Soong SJ. Transvaginal sonography of the endometrium in postmenopausal women. Obstet Gynecol. 1991;78:195-9.

7. Granberg S, Wikland M, Karlsson B, Norstrom A, Friberg LG. Endometrial thickness as measured by endovaginal ultrasonography for identifying endometrial abnormality. Am J Obstet Gynecol. 1991;164:47-52. 
8. Refaie A, Anderson T, Cheah SS. Out-patient Hysteroscopy: findings and decision making for treatment of abnormal uterine bleeding in pre- and post-menopausal women. Middle East Fertil Soci J. 2005;10(1):43-8.

9. Elewa AM, El Karim MA, Saad SA, Ramadan MA, El Hai MA. Correlation of vaginal ultrasound and hysteroscopy with endometrial histopathology in postmenopausal women. Middle East Fertil Soci J. 2001;6:26-33.

10. ParkK.Park's Textbook of Preventive Medicine; Screening for Disease. $23^{\text {rd }}$ edition. Jabalpur: $\mathrm{m} / \mathrm{s}$ Banarsidas Bhanot; 2015:140-7.

11. Sousa R, Silvestre M, Almeida e Sousa L, Falcao F, Dias I, Silva T, et al. Transvaginal ultrasonography and hysteroscopy in postmenopausal bleeding: a prospective. Acta Obstet Gynecol Scand. 2001;80:5.

12. Yela AD. Comparative study of transvaginal ultrasound and outpatient hysteroscopy for diagnosing pathologic endometrial lesions in postmenopausal women. Rev Assoc Med Bras. 2009;55(5):553-6.

13. Kaul I, Kalsi M, Anand AK, Jad R, Menia V. Transvaginal sonography versus histopathology in postmenopausal bleeding: a prospective study. JK Sci. 2012;14(3):129-33.

14. Verma R. A study on abnormal uterine bleeding in perimenopausal age in rural Bihar. JMSCR. 2016;4(2):9262-74.

15. Naik VS, Rege JD, Kusum DJ. Pathology of genital tract in postmenopausal bleeding. Bombay Hospital J. 2005;47:14-7.

16. Sengupta A. A study of 50 cases of post-menopausal bleeding. J Obstet Gynecol India. 1989:577-81.

17. Gao X. A study on 234 postmenopausal women at WCUMS, Chengdu. Brit J Obstet Gynecol. 2002.

18. Ahmed JA. Clinico pathological evaluation of postmenopausal uterine bleeding in Mosul City. Tikrit Med J. 2007;13:73-8.
19. Karlson B, Granberg S, Ridell B, Wikland M. Endometrial thickness as measured by transvaginal sonography: interobserver variation. Ultrasound Obstet Gynecol. 1994;4(4):320-5.

20. Bakour SH, Dwarakanath LS, Kahn KS, Newton JR, Gupta JK. The diagnostic accuracy of ultrasound scan in predicting endometrial hyperplasia and cancer in postmenopausal bleeding. Acta Obstet Gynecol Scand. 1999;78:447-51.

21. Grandberg S, Wickland M, Karlsson B. Endometrial thickness as measured by endovaginal ultrasound for identifying endometrial abnormalties. Am J Obstet Gynecol. 1991;164:47-52.

22. Cacciatore B, Ramsoy T, Lehtoirta P, Ylostalo P. Transvaginal sonography and hysteroscopy in postmenopausal bleeding. Acta Obstet Gynecol Scand. 1994;73:413-6.

23. Nasri MN, Shepherd JH, Setchell ME, Lowc DG, Chard T. The role of vaginal scan in measurement of endometrial thickness in postmenopausal women. $\mathrm{Br}$ J Obstet Gynecol. 1991;98:470.

24. Mathlouthi N, Slimani O, Ferchichi A, Ben Temime R, Makhlouf T, Attia L, et al. Postmenopausal bleeding. Comparison between ultrasonography, hysteroscopy and histology results. Tunis Med. 2013;91(2):99-103.

Cite this article as: Bhangale SV, Sharma S, Patil A, Kumari B. Evaluation of endometrial causes of postmenopausal bleeding with it's correlation with endometrial thickness and hysteroscopy findings and endometrial tissue histopathology. Int J Reprod Contracept Obstet Gynecol 2020;9:2940-7. 